\title{
Game Selection Method for Game-Based History Learning
}

\author{
Woo-Hyun Lee, Won-Hyung Lee* \\ Chung-Ang University, 84 Heukseok-ro, Dongjak-gu 06974, Korea \\ *Corresponding author: Won-Hyung Lee, whlee@cau.ac.kr
}

\begin{abstract}
Games that are used in research on game-based learning and serious games that are used for education are usually exclusive, making it difficult for teachers to attempt new methods in education. According to the data published in 2009 by the European Schoolnet (EUN), a network of European Ministries of Education, most of the problems that teachers face when using games in class are related to game selection. Based on the aforementioned data, this study presents a set of criteria for selecting games in order to solve the inconvenience experienced by teachers. The games, which are used as teaching materials for game-based learning, have been replaced with commercial games that are easily purchased, rather than serious games that are difficult to obtain the licensing. Based on the criteria, two games were selected in this study and the classes were conducted at the educational site. Compared to the group trained with textbooks, it has been confirmed that the effect of game-based learning was sufficient. In addition, five out of ten problems that teachers face were resolved.
\end{abstract}

Keywords: Game-based learning; History education; Commercial game; Reenactment of history learning

Publication date: October 2021; Online publication: October 29, 2021

\section{Introduction}

The importance of history education is emphasized in every country and culture. Rather, the more advanced a country is, the more important its history becomes, and more support is provided for history education. Korea, which is the only divided country and is constantly in controversy with its neighboring countries in regard to historical issues, needs a lot of investment and nurturing of interest in history education.

Efforts to use games in education have steadily continued for over a decade. Professor Jong Hyun Wi, from Chung-Ang University, introduced the concept of game-based learning (GBL). In this concept, games are being introduced into education ${ }^{[1]}$, and it has proven its effectiveness through various educational experiments, such as in mathematics, English, politics, and economics. He applied a MMORPG (massively multiplayer online role playing game) called Sky Island Online in mathematics education, and there were positive results in terms of confidence and attitude toward mathematics ${ }^{[2]}$. In a previous study, it has been pointed out that the games used for education are usually simple flash games or games that are played alone without being connected to a network, and the results achieved from those are also plain. English classes were divided into 50 minutes of game-based classes using a MMORPG and 50 minutes of in-depth classes to evaluate the contents of the study. In order to derive the results from using the game while teaching English reading and communication, an English test was held at the end of the experiment, which showed a significant difference in their scores ${ }^{[3]}$. For politics and economics students, after game-based classes, their understanding and interest were investigated through questionnaires and the results obtained were as expected ${ }^{[4,5]}$. As such, studies on the use of games that have been effective in various subjects, theories that combine them, and examples of actual class application have been conducted; however, studies on the use of games in history are still insufficient. 
Educators who observed the disadvantages of instillation type education in the past came up with various types of contents, such as movies and cartoons, to help students understand history through storytelling. Games also consider storytelling as the most important factor in determining immersion; thus, history education, where storytelling is important ${ }^{[6]}$, will be one of the subjects that will have the greatest advantage in the form of a game.

In this study, using highly accessible commercial games in history education for elementary school students is the subject of this study. Advantages such as storytelling and experiential learning of games based on history are also used in this study. The advantages of history-related games come from those that have a positive effect on increasing immersion in the story, so they are tested based on the hypothesis that they will work in favor of teachers who teach, and then a survey is conducted among the teachers who participated in the study.

\section{Use of games in the educational field}

Since educators communicate knowledge via interaction with students, the means to inspire students' concentration has become a subject of research regardless of the period. As one of these means, the concept of gamification or GBL in today's classes is being developed in various directions because of its effectivity by adding fun elements of a game. "Gamification" is a concept of adding play elements to fields other than games, and it is commonly used to give small scale goals and rewards. For example, having a quiz without scoring the results as a test is the most common gamification; in addition, a serious game that develops the content itself into a complete game also falls within the gamification category. Furthermore, GBL is a concept that utilizes educational elements in a game and a way for learners to learn something while playing games.

Recently, gamification has been considered a promising future educational approach, making it one of the most favored areas in academic research and development ${ }^{[7]}$. GBL is a concept that utilizes educational elements in a game, with the learners achieving the learning goals using a computer game that integrates educational contents into games without the direct involvement of teachers ${ }^{[8]}$. In addition, game-based learning acts as a tool for learners to learn through interactive learning, such as audio-visual capabilities, animations, videos, and games ${ }^{[9]}$. Taevs and other researchers have suggested that semantic representations of auditory or visual stimuli and expressions in different modalities facilitate the formation of cognitive maps ${ }^{[10]}$. Lammert-Siepmann and other researchers have mentioned that memory performance in regard to object identity improves when visual communication and auditory communication occur simultaneously [11].

Serious games are games that aim to not only employ entertainment elements but also solve real world problems ${ }^{[12]}$. However, serious games are currently being developed in the direction that focuses only on educational efficacy ${ }^{[13-15]}$. Most learning contents are designed to determine the achievement effects of learning or training using research data on the achievements of serious games or reports from public institutions in regard to games while verifying the impact and performance of serious games ${ }^{[16-18]}$. However, when planning to educate using actual games, it is necessary to discuss on how many classes to teach, starting with installing the games that have been selected. Even if the efficacy of serious games is academically proven, it is difficult use them in actual education if their accessibility is low ${ }^{[19]}$. Developing a game requires a lot of resources, from graphics to sounds, and many advanced personnel who are capable of designing or coding, depending on the size of the game. There is a limit to covering these costs without investments. However, investments are usually made in profitable areas; it is difficult to expect high profits from serious games that are aimed at education.

Jeong and Lee have stated that serious games have an intentional purpose and should be purpose oriented from the planning stage ${ }^{[20]}$. Serious games that are created for education already have excellent 
functions as educational materials to suit the purpose of development. The problem is that developing this kind of educational materials requires more effort and resources than writing a single book. Compared to traditional education, serious games can promote concentration through having fun, but the marketability is inferior as the genre is not popular. Products with poor marketability do not make good investments, leading to a decline in game quality and productivity. Serious games with low productivity have a narrow range of choices, and because they are mainly used for academic purposes, they are not easily shared, thus having low accessibility.

In Europe, research has been conducted for a long time where advanced technologies and creative concepts are applied to education. European Schoolnet (EUN) is a network that researches and shares these teaching methods, with 34 participating Ministries of Education. The problems arising from the use of games for educational purposes, as indicated in a report released by EUN in 2009, are shown in Table 1 [21]. The problems introduced in the report are all directly or indirectly related to the selection of games that are suitable for education. This shortcoming is revealed in the plan to use commercial games, instead of serious games in education.

Table 1. Problems of using games in education

\begin{tabular}{cc}
\hline Rank & Reason \\
\hline 1 & Cost and licensing \\
2 & Schools timetable \\
3 & Looking for suitable games \\
4 & Attitudes of teachers \\
5 & Training and support \\
6 & Inappropriate contents \\
7 & Worries about negative aspects \\
8 & Insufficient evidence of value \\
9 & Examinations \\
\hline
\end{tabular}

\section{Prior research}

In 2005, Professor Akira Baba from Tokyo University began researching with Koei and conducted a study in which two online games, "Uncharted Waters" and "The Ambition of Nobunaga," were adopted as historical textbooks for first and second graders. It has been reported that the online games had a positive effect on improving learning motivation, increasing physical knowledge, raising awareness of the historical era, as well as improving cooperation and communication skills ${ }^{[22]}$.

At the 2008 Korea-Japan Joint International Symposium on the Utilization of Online Game Education, Professor Akira Baba demonstrated the effectiveness of indirect history experiences in games, and Professor Jong Hyun Wi from Chung-Ang University defined online games as G-Learning, using MapleStory and Online ${ }^{[23]}$.

Kim and Kim have proved that games do contribute to the development of historical thinking skills by applying a simulation game, Civilization V, in middle school classes. Through that, students are given opportunities to experience historical events and characters. Although the research had led to the distortion of students' perception of history, it drew attention by removing anxiety and raising questions about inaccurate re-enactments through textbook-linked learning. However, they concluded that since there are practical restrictions for students to practice in school sites along with limited class hours, it would be appropriate for exploratory learning activities, but a lot of time is required to achieve results in on-campus classes ${ }^{[24]}$. Hong and Jin developed a serious game for elementary history learning and conducted a study 
to determine students' satisfaction ${ }^{[25]}$, while Lee and Kim discussed the process of developing a serious game for history education and a method was proposed for inducing participation by providing a task involving content related to historical events ${ }^{[26]}$. In Europe, the research on game-based learning is active and investments are well-coordinated. In Scotland, more than 500 teachers have participated in the game education project, the Consolarium. In Denmark, the trade simulation game, Patrition 3, have been used for history education, and feedbacks were provided to parents in terms of the learning outcomes. Patrition 3 is a game in which players take on the role of traders and experience the history of Denmark in the Middle Ages ${ }^{[27]}$.

Game-based learning appeals more strongly to male students than to female students. A survey that was conducted by a market research firm, The NPD Group, Inc., found that male students have higher level of knowledge in regard to computers and games, but since 2013, the interest among female students have been increasing linearly ${ }^{[28]}$, especially in simulation-based education, female students have shown more interest ${ }^{[29]}$. A study found that children age 6 to 12 years old tend to welcome games in learning difficult topics as they provide an interesting perspective for problem-solving, promote learning, and increase their interest in topics ${ }^{[30-33]}$.

Jung investigated the effect of simulation game-based learning on students' academic sentiment and achievement ${ }^{[34]}$. As a tool for measuring academic sentiment, a total of 40 questionnaires were formed based on the achievement emotions questionnaire developed by Pekrun ${ }^{[35]}$. It has been verified that negative academic emotions including anger, anxiety, and boredom can be reduced through game-based learning. As a measurement tool for academic performance, two high school social teachers revised the competition examination questions issued by the Education Association to suit the learners' level. They prepared and used a total of 25 questions by verifying the validity of the contents. In the study, each student learned about stock investments through a simulation game. There was no significant difference when comparing academic performance with instructor-led education. Unlike the findings from the research conducted by Akinsola ${ }^{[36]}$ as well as Sowunmi and Aladejana ${ }^{[37]}$, which demonstrated a correlation between game-based learning and academic performance, she mentioned that "using other types of simulation games" and "minimizing the role of professors" are reasons for not observing the rise in academic performance. However, it is worth noting that game-based learning minimizes the role of professors and has positive effects on academic sentiments but leads to the same academic performance.

Microsoft, an American IT (information technology) company, has been conducting an educator training program called Microsoft Innovative Education Experience (MIEE). Microsoft also offers guidelines on creative education, including game-based learning ${ }^{[38]}$.

\section{Games selection for experimentation}

\subsection{Criteria for the selection of games}

The criteria for the selection of games in this study are listed below.

(1) The historical context must be clear and the historical elements that should be taught through the game include characters, culture, and technology. Games with ambiguous contexts are unsuitable for history education such as the historical characters did not actually live in the same period, or the historical context does not match.

(2) There should be no problems with the historical evidence. In most FPS (first person shooting) games, there are issues related to firearms; thus, this part can be skipped personally as the difficulty of the test is high, but it is necessary to be careful because it can instill inappropriate knowledge in students. The historical evidence should be referred to several internet communities. This is not an official 
indicator; however, with many netizens participating, discussing, and pointing out any games with problems, it is possible to assist in selecting the games to be selected for this study.

(3) There should be no distortion of history. Errors occurring in (1) and (2) above can be corrected by educators in the curriculum, but distortion of history refers to problems that would not end in private affairs. For example, among the games set in the Second World War, there was a game with errors (WW2: Shattered Europe), in which Finland fought with the Allies while Sweden and Spain participated in the Axis. Games that are expected to have such inaccuracies were excluded from the study.

(4) The cost of the license should be capped at about $\$ 30$ and should be easily accessible.

\subsection{Feasibility study for analysis criteria}

Historical thinking and re-enaction have been mentioned as a result of a number of studies on historical game-based learning that have been discussed so far. The Ministry of Education aims to educate the next generation with historical facts and the inherent historical values in them, so that students can comprehensively understand the activities of Korean people and today's Korean phenomenon from a historical perspective. To this end, the aim is on fostering historical thinking ${ }^{[39]}$.

Historical thinking skills vary according to the opinions of historical educators, and the emphasis should be on logical thinking and ways to develop historical imagination. The term "re-enaction" is a phenomenological term that refers to feeling someone's experience as if one was experiencing it again. Collingwood, a British philosopher and historian, approached history by attempting to conceptualize the past through evidence ${ }^{[40]}$. However, most evidence is not sufficient or decisive enough to confirm the process of a historical actor's thinking. Furthermore, humans behave differently under the same circumstances, so reconstructing the behavior of a historical actor is the application of one's thinking from the perspective of the actor based on the assumption that the actor would have done this in this particular situation ${ }^{[41]}$. In fact, dramatization learning, role-playing, history writing, model-making, history trials, history diaries, and history drawing can be considered as approaches to learning history by reenactment ${ }^{[42]}$. In other references, there were cases where historical newspapers were published. Lee proposed three educational effects through experiential historical learning ${ }^{[43]}$.

First, through critical and reflective thinking, the historical behavior, that is the subject of learning, is not accepted as fixed, but can always be selected and developed under one's own control.

Second, by reenacting historical behavior, the historical behavior becomes the learner's own behavior, which means that the learner is transformed into a new self. Therefore, learners themselves can constantly change according to the changes in the historical world.

Third, learning by imaginatively participating in historical behavior enables interaction between historical behavior and learners. Learning and behavior are not separated from knowledge, attitudes, and values, but are integrated into one by an activity called imaginary participation, which means that learning becomes an active process. Furthermore, the subject can induce motivation for learning by having a close exchange with the learning subject.

Through historical reenactment, students experience more than just historical evidence as a subject of learning but understand the history at the period being considered. Therefore, historical reenactment classes are appropriate for cultivating historical thinking, the goal of history education. It can be called a teaching method ${ }^{[44]}$. 


\subsection{Analysis of the selected games}

\subsubsection{The Wednesday}

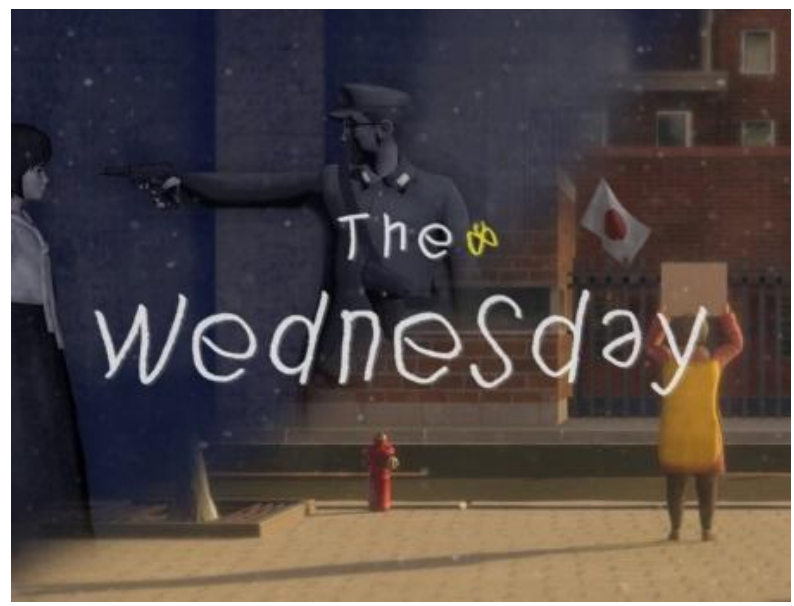

Figure 1. The Wednesday

An elderly lady, who was protesting in front of the Japanese Embassy in 1992, suddenly returns to the day before her friends disappeared in 1945. At that time, the lady was a comfort woman in the Japanese military. It is a puzzle adventure game in which she finds clues about her friends' disappearance and attempts to discover the truth.

Since it introduces the daily experience of the victims as comfort women and the past activities of Japanese imperialism, such as the Japanese Army Unit 731, Maruta, and Unit 1644, it allows the players to think about aspects of the war, which are not covered in existing history textbooks. It makes the players feel like they are experiencing their own story, not someone else's. This is because the players would feel that they have created the story by direct manipulation. In this immersive situation, it is expected that the players would experience empathy and loss. The total play time is three to five hours, but since it comprises of several chapters, only one chapter is taught per class. Since its license can be purchased at a cost of about $\$ 14$ and can be easily installed through a web platform, this game was selected in accordance with the selection criteria.

Hwang Yoo-jung, who was in charge of the story of this game, mentioned in an interview with a media company, Maeil Economy, "Starting by reading the testimonies of comfort women victims published in Korea, it laid the foundation for historical accuracy through articles on related topics, national reports, and academic journals. In addition, I also referred to books, newspapers, interviews, and news materials that are related to that topic. As the background of the game is foreign and victims of various nationalities appear in the game, I studied not only Korean cases but also foreign ones. I also consulted foreign news articles and publications, such as government reports on biological experiments conducted by the Japanese military and special features of Korean comfort women victims published by Indonesian magazines in the past. 'Grandma Soon-Yi's study,' which has been established based on such historical evidence, plays a key role in uncovering the truth of the past." 


\subsubsection{Valiant Hearts: The Great War}

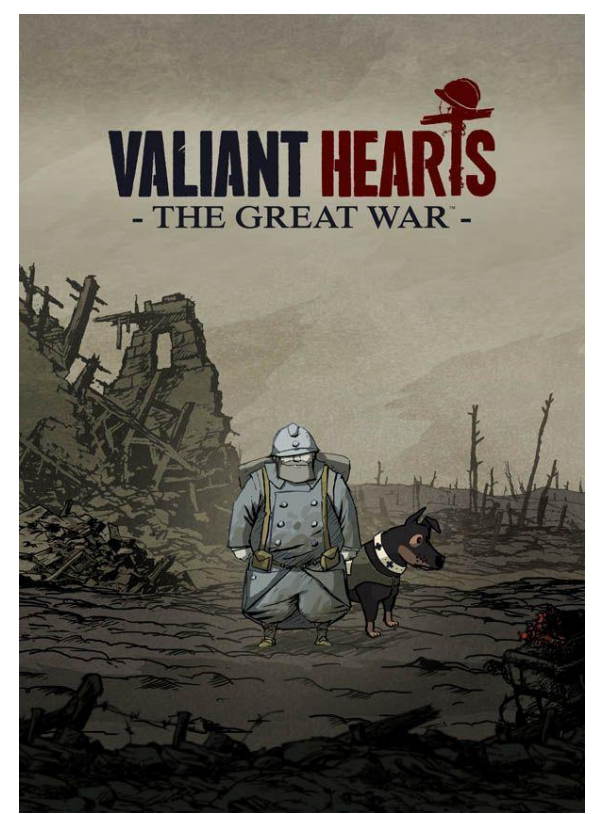

Figure 2. Valiant Hearts: The Great War

This game was created as a scenario based on an anecdote that would have occurred between 1914 and 1918, when the First World War took place. The main character of this game is not a war hero. It concerns the forced recruitment of soldiers during the war, fighting or fleeing, and surviving, using the surrounding terrain. In the process, all of the hero's companions are killed by guns or shells, showing the tragedy of war. The game begins with the assassination of Franz Ferdinand, just as in real history. With the historical declaration of war by Germany on Russia, the protagonist, an ordinary farmer in France, is drafted into the army and the game begins. With the historical facts that emerge in this process, it is possible to generate an interest in the First World War and induce the conscripted protagonist to empathize with the pain of the war through victims he encounters while surviving it. Since the protagonist is an ordinary citizen, it is expected that students' empathy can be elicited, and through this, an experiential learning of history can be established. The flow of the game starts with a story and cycles through puzzle-action-story. In regard to that, a rotation of one cycle is used in one lesson. This game can be easily purchased on a web platform for about \$15. As shown in Figure 3, an in-game menu has been created so that the players would be able to gather historical facts and understand other parts of the game.

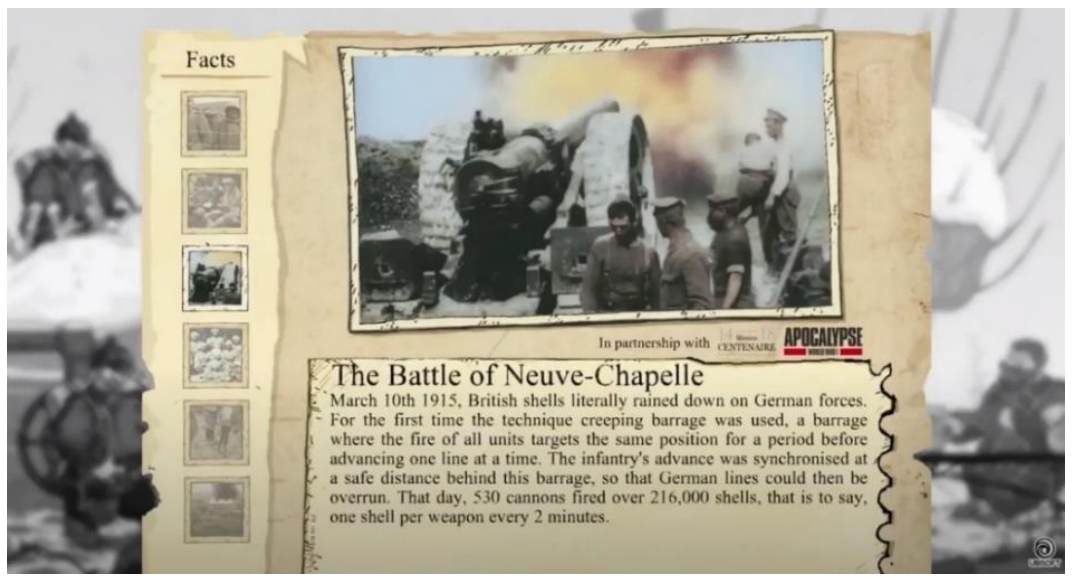

Figure 3. Differences between real facts and the game can be found in the game menu 


\section{Experiment}

\subsection{Experimental method}

In this study, an experiment was carried out on elementary school students who had never learned history by comparing two types of groups: the first type included groups that used games in the teaching process and the second type included those that only used textbooks. According to the curriculum set by the Ministry of Education, history lessons begin from the first grade of middle school. Therefore, 128 6th grade elementary school students, who were a grade lower than first grade middle school students and had the closest learning ability to these students, were included in this study. Sixteen groups of eight students were formed, half of which were under the game-based learning, and the other half were taught with only with textbooks. Sixteen teachers, who had different levels of experience ranging from two to ten years, were selected to participate in this study. The teachers conducted the classes an hour a week for a total of eight weeks, of which four weeks were for game-based learning groups and the other four weeks for the textbook learning groups, so that they could experience both teaching methods.

The students in the game-based learning groups were not allowed to play the games separately; only the teachers played the games as a representative because it is important for students to focus on the same screen while the teacher is explaining the background. For the first 45 minutes, the games were used to educate, and for the next 15 minutes, textbooks were used, and the classes were conducted in a way to organize what was learned earlier. The other groups were taught in the same scope from the first week using textbooks. Among the middle school history textbooks as shown in Table 2, "World War and Social Change" in the world history and "Changes in Joseon's Society" in the Korean history were selected as they are related to the games' historical context.

Each textbook consists of six sections, and it is ideal to spend four weeks per unit considering the vacation and exam period; thus, the study period was for four weeks each with 8 weeks in total.

Table 2. Expected learning effects from various game genres

\begin{tabular}{cc}
\hline \multicolumn{1}{c}{ World history } & Korean history \\
\hline $\begin{array}{c}\text { The emergence of civilization and the formation of the } \\
\text { ancient world }\end{array}$ & $\begin{array}{c}\text { Prehistoric culture and the formation of ancient countries } \\
\text { cultures }\end{array}$ \\
$\begin{array}{c}\text { The spread of world religions and the formation of local } \\
\text { Exchange and change in the local world }\end{array}$ & $\begin{array}{c}\text { The development of the era of the north and south countries } \\
\text { Imperial invasion and movement to build a nation-state } \\
\text { World war and social change }\end{array}$ \\
Development and challenges in the modern world & $\begin{array}{c}\text { Establishment and development of Joseon } \\
\text { Chang in Joseon's society }\end{array}$ \\
\hline
\end{tabular}

The teaching of each group was kept confidential from the other groups. The teachers were instructed to organize a question-and-answer time for at least 5 minutes, up to 30 minutes, as well as record the questions related to the class. As a result, the groups with game-based education maintained a higher level of question count and discussion time, while the groups trained with textbooks from the beginning gradually decreased in terms of the question count and the discussion time. 


\subsection{Result and discussion}

Table 3. Number of questions and discussion time for each group

\begin{tabular}{ccccc}
\hline & \multicolumn{2}{c}{ Game-based education } & \multicolumn{2}{c}{ Textbook education } \\
\hline Time & Question count & Discussion time & Question count & Discussion time \\
\hline 1 & 11.125 & 18 & 10.5 & 15 \\
2 & 12.5 & 21 & 9.375 & 13 \\
3 & 12.125 & 20 & 9.125 & 11 \\
4 & 13.375 & 23 & 8.125 & 10 \\
5 & 10.25 & 15 & 6.375 & 6 \\
6 & 11.125 & 14 & 8.25 & 8 \\
7 & 10.675 & 13 & 7.125 & 9 \\
8 & 14.375 & 19 & 7.875 & 11 \\
\hline
\end{tabular}

As shown in Table 3, the results of the eight-week training showed that the question counts of the game-based education groups averaged to 11.943 and the average discussion time was 17.875 minutes, maintaining a higher level compared to the textbook groups (8.343 times and 10.375 minutes). The groups that were taught with textbooks from the beginning showed a high level initially alike the game-based groups, but the number and time gradually decreased over time. The reason why the discussion time was not accurately measured was that the end of the conversation was not clear, so additional question time was given after the discussion on the topic. The time was measured by rounding off the discussion time. This comparison is a process to determine whether the lessons in the study demonstrated the effectiveness of proper game-based learning. It has already been revealed by prior research that game-based learning is well received in terms of students' interest. Therefore, this concludes that game-based learning has been performed effectively in this study; thereby, it is able to move on to the next phase.

After the experiment, the teachers were requested to fill in a questionnaire to find out any inconveniences they had encountered during the game-based lessons. The questionnaire was based on their discomfort with game-based education as listed in Table 1. The teachers were instructed score each item from a score of 0 to 10 . The higher the score, the more positive the survey is designed to be evaluated. The contents of the questionnaire, the teachers' reviews, and their results are shown in Table 4.

Table 4. Teacher's complaint assessment survey for game-based learning based on EUN report

\begin{tabular}{|c|c|c|c|}
\hline No. & Survey & Average score & STDEVP \\
\hline \multicolumn{4}{|c|}{ 1. Cost and licensing } \\
\hline $1-1$ & $\begin{array}{l}\text { The purchase costs of the selected games used in the experiment were } \$ 14 \text { and } \$ 15 \text {, } \\
\text { respectively. Do you think these prices are reasonable as teaching materials? }\end{array}$ & 8.06 & 1.02 \\
\hline \multicolumn{4}{|c|}{ 2. School timetable } \\
\hline $2-1$ & $\begin{array}{l}\text { The classes lasted for } 1 \text { hour and } 30 \text { minutes. Did you have enough time to explain } \\
\text { while playing the game? }\end{array}$ & 6.12 & 0.992 \\
\hline $2-2$ & $\begin{array}{l}\text { The classes in elementary schools are for } 40 \text { minutes. Will you be able to proceed } \\
\text { smoothly if you carry out this kind of classes for } 40 \text { minutes? }\end{array}$ & 5.18 & 1.285 \\
\hline \multicolumn{4}{|c|}{ 3. Finding suitable games } \\
\hline $3-1$ & $\begin{array}{l}\text { When you were preparing for the class with the selected game, were there many } \\
\text { elements to explain to the students? }\end{array}$ & 7.37 & 1.452 \\
\hline $3-2$ & If you teach in this way, can you find another game to use as a teaching material? & 3.81 & 1.130 \\
\hline
\end{tabular}




\begin{tabular}{|c|c|c|c|}
\hline No. & Survey & Average score & STDEVP \\
\hline \multicolumn{4}{|c|}{ 4. Attitudes of other teachers } \\
\hline $4-1$ & $\begin{array}{l}\text { Can you explain directly to other teachers or parents about the effectiveness of } \\
\text { game-based education and persuade them to change their way of teaching? }\end{array}$ & 3.56 & 1.058 \\
\hline \multicolumn{4}{|c|}{ 5. Training and support } \\
\hline $5-1$ & $\begin{array}{l}\text { You have tried installing, running, and playing. If you use other games as teaching } \\
\text { materials in the future, would you be able to play without help? }\end{array}$ & 4.12 & 1.964 \\
\hline $5-2$ & $\begin{array}{l}\text { Do you think that if other teachers carry out game-based education classes in this } \\
\text { way, they will be able to conduct classes without extra training? }\end{array}$ & 3.68 & 1.609 \\
\hline \multicolumn{4}{|c|}{ 6. Inappropriate content } \\
\hline $6-1$ & $\begin{array}{l}\text { Were there any inappropriate contents for education in the selected games for this } \\
\text { study? }\end{array}$ & 8.18 & 0.881 \\
\hline \multicolumn{4}{|c|}{ 7. Worries about negative aspects } \\
\hline $7-1$ & $\begin{array}{l}\text { Was there any expected negative effect? (The lower the score, the lower the } \\
\text { expected negative effect.) }\end{array}$ & 6.93 & 1.028 \\
\hline \multicolumn{4}{|c|}{ 8. Insufficient evidence of value } \\
\hline $8-1$ & $\begin{array}{l}\text { You were given an explanation of the pros and cons of game-based education based } \\
\text { on other studies before carrying out this experiment. After experiencing game- } \\
\text { based education through this study, do you agree with the pros and cons of other } \\
\text { studies? }\end{array}$ & 7.93 & 0.826 \\
\hline \multicolumn{4}{|c|}{ 9. Examinations } \\
\hline $9-1$ & $\begin{array}{l}\text { The games that were selected for the study have related sections to elementary } \\
\text { school Korean history and world history textbooks, respectively. Were the contents } \\
\text { of the game appropriate for explanation in relation to the contents of the textbook? }\end{array}$ & 6.43 & 0.863 \\
\hline $9-2$ & $\begin{array}{l}\text { If the sections mentioned in 9-1 are tested, do you expect the experience of the } \\
\text { game to help with the test? }\end{array}$ & 8.62 & 1.053 \\
\hline
\end{tabular}

In regard to the average score, 8 points or more are considered as improved, 5 points or more but less than 8 points are considered as minor improvements or improvements, 2 points or more but less than 5 points are considered as require improvements, and less than 2 points are subjected to significant changes in the experimental method.

In the above questionnaire, the teachers gave a high score to items $1,6,8$, and 9 in addition to question 3-1. There was also a positive evaluation toward the selected games. However, question 3-2 (3.81), which evaluated the selection of other games, scored low. They also spoke of the difficulty in selecting new textbooks. The teachers agreed that this study was in line with the positive effects of game-based learning, which solved the problem of the lack of evidence (7.93). However, they felt that it was somewhat difficult to persuade other teachers and parents with this value, thus scoring lower in item 4 (3.56). They also believe that such special education requires sufficient training and research. They evaluated that special experience would help children learn better. According to the contents in Table 1, items corresponding to 1, 2, 3, 5, and 6 are related to the selection of educational materials games ${ }^{[45]}$. Among these items, only 2 and 5 remain as tasks to be solved, excluding those that have been resolved through the questionnaire in Table 4. However, it can be asserted that item 2 cannot be solved by using commercial games. Play time is an element to evaluate "fun" in commercial games. A game with a fixed end may have a short play time, but not many users would pay game companies to enjoy a play time as short as class time. If so, class time would have to be extended for a longer period or playing games has to be made as a task outside class time; 
neither students nor parents or teachers would want this method.

Questions 5-1 and 5-2 in Table 4 have 4.12 and 3.68 points, respectively. Many improvements are required if the score is between 2 to 5 points. The teachers believe that is necessary to build an infrastructure for game-based learning to be applied in real education sites. In modern society, computers and mobile devices are widely used to play games, but there is a possibility of discrimination due to problems such as school finances and the gap between the rich and the poor in schools without any support. In addition, information sharing is essential because it would be burdensome for teachers to individually investigate inappropriate elements in various games, playtime, and the related contents of textbooks. The low score of question 4-1 (3.56) reflects the difficulty and burden felt by teachers in proving the effectiveness of gamebased education; thus, the construction of an infrastructure and support should be preceded to change the negative social awareness.

In this study, the limitations of the development scale and accessibility of serious games for gamebased education are recognized. Therefore, commercial games are sought to be used in education as an alternative. According to the results of previous studies, one of the main reasons why game-based education cannot be applied smoothly in real settings is the perception of teachers and their willingness to play games. Since serious games are not as bad as people's negative perception toward other games, the majority of previous studies about game-based education have included serious games. Studies on game-based education using serious games such as Gounaridou's "Educated Transportation Behavior and Safety Awareness Using Serious Games" [46], Chen's "Creating Mobile Games to Investigate Learning Interest by Game Type" [47], and Pombo's "Study on the Educational Value of Augmented Reality Games" [48] are characterized by proving the effectiveness of game-based learning based on handmade games. Since these proven systems have not been shared with teachers and are not accessible after the studies, there are no available games to use as classroom materials for game-based education by referring to the proven effects from the aforementioned research. Through the effect of game-based learning, this study was conducted with a sense that it would be meaningless if it is not actually used in real settings but only in studies where students' concentration has improved, and their scores have increased. Teachers, as one of the subjects of the study, were asked to prepare themselves for the lessons, whereby they had to install the games by themselves and prepare the lessons without knowing the name of the game. Since the missions given to the players by the commercial games are different from the desired goals of the teachers, the teachers who participated in the study encountered difficulty while preparing for their lessons. However, as communications between teachers were not controlled throughout the four weeks, the teachers shared a method to overcome their discomfort, and as time passed, their preparation for the lessons became smoother, which was the same as the intended result of the study.

\section{Conclusion}

The game-based lessons in this study were conducted in such a way that the teachers acted as representatives to play the games while providing additional explanation, and the students, on the other hand, watched and listened to their teachers. This study was designed in consideration of the universal classroom environment. In general, classes held at schools involve one teacher dealing with multiple students. When multiple students play games at the same time, their speed of progress still varies; thus, teachers need to explain several times. In addition, there are many cases where there are insufficient facilities for multiple students to play at the same time. Therefore, the speed of the class depends on the speed of the teacher, which is not a problem in game-based learning because it depends on the teacher's ability, not only in game-based lessons but also in textbook-orientated lessons. It was an impossible approach in the previous generation when games were considered enjoyable only to players, but it is only worth trying in today's generation, who are familiar with games viewed through live streaming. The problem with games is that the range of 
history that can be explained through the game's story is limited; however, contents that are delivered through screen media such as movies and drama can be additionally selected for learning. This is because the game industry has a shorter development period than other forms, and it is difficult to produce games based on true stories, thus limiting the number of suitable games.

The importance of history education is always being emphasized, and the effectiveness of game-based education is continuously verified through other studies. In the case of the United States, Japan, and advanced countries in Europe, various attempts have been made to apply game-based education in regular classes over the last decade; however, in Korea, education using games is in a state of inadequate development.

This study, which began with the aim of solving the inconveniences faced by teachers who use games as educational materials, focused on solving the problems based on what has been reported in the EUN report. One of the most appropriate subjects to use games in education is history. Therefore, historical game selection criteria and evaluation indicators were set for the study among elementary school students. Different games have different elements that can be used in education. As one of the ways to solve "teacher's hard work" as an inconvenience among educators, this study presented examples of using various games by combining games with various elements. In order to do so, leading game-based learning cases were examined and the factors that history games should have for history education were determined to use them in this educational research. The students' question count and discussion time were evaluated, and the teachers' reviews about game-based education were gathered. The study showed that the question count and discussion time of the game education groups were significantly higher than those of the textbook education groups; in addition, in regard to the teachers' evaluation, 3 out of 13 questions improved and 6 slightly improved.

Alike students who exhibit more interest when learning historical periods in history books while watching historical dramas or movies relating to the context of the period, more history-related games are being developed and researched in order to produce the same effect. If these games can be used for education, it is expected that, ultimately, the general perception of games will move in a more positive direction.

\section{Funding}

This work was supported by the Ministry of Education of the Republic of Korea and the National Research Foundation of Korea (2019S1A5C2A04082405).

\section{Disclosure statement}

The authors declare that there is no conflict of interest.

\section{References}

[1] Wi J, Kim T, 2010, Academic Effectiveness of G-Learning - The Effect on the Academic Achievement of Elementary School Students. Digital Imaging Journal, 7: 67-82.

[2] Wi J, Cho D, 2020, The Effect of G-Learning Towards a Student's Affective Domain in Math Subject. Journal of Korea Game Society, 10: 37-45.

[3] Wi J, Won S, 2014, Suggesting Effectiveness of G-Learning English Afterschool Program in Elementary Schools. Foreign Languages Education, 21: 137-163. https://doi.org/10.5392/JKCA.2012. 12.10 .541 
[4] Wi J, Oh N, 2005, The Effects of Economy Education through MMORPG. Journal of Korea Game Society, 5: 13-22.

[5] Wi J, Won E, 2009, Utilizing an Online Game, 'Goonzu'. Journal of Korea Game Society, 9: 83-93.

[6] Kim Y, 2006, The Root Cause of Tension and Immersion: Why You Have to Immerse Yourself in the Game. Digital Storytelling Research, 1: 1-14.

[7] Juho H, Koivisto J, Sarsa H, 2014, Does Gamification Work? A Literature Review of Empirical Studies on Gamification, in 47th Hawaii International Conference on System Sciences 14, Waikoloa, Hawaii, 3025-3034. https://doi.org/10.1109/HICSS.2014.377

[8] Prensky M, 2001, Digital Game-Based Learning, McGraw-Hill, New York, NY.

[9] Chen PC, 2010, New Trend of Electronic Textbooks. Education Sciences, 516: 36-40.

[10] Taevs M, Dahmani L, Zatorre RJ, et al., 2010, Semantic Elaboration in Auditory and Visual Spatial Memory. Front Psychol, 1(10). https://doi.org/10.3389/fpsyg.2010.00228

[11] Lammert-Siepmann N, Bestgen AK, Edler D, et al., 2017, Audiovisual Communication of ObjectNames Improves the Spatial Accuracy of Recalled Object-Locations in Topographic Maps. PLoS ONE, 12. https://doi.org/10.1371/journal.pone.0186065

[12] Alvarez J, Djaouti D, 2011, An introduction to Serious game - Definitions and Concepts. Serious Games \& Simulation for Risks Management, 11: 10-15.

[13] Han H, 2010, A Study on Conceptual Definition and Types of Serious Games. Humanities Content, 19: 219-236.

[14] Kaasinen A, 2019, Plant Species Recognition Skills in Finnish Students and Teachers. Education Sciences, 9(85). https://doi.org/10.3390/educsci9020085

[15] Chen MHM, Tsai ST, Chang CC, 2019, Effects of Game-Based Instruction on the Results of Primary School Children Taking a Natural Science Course. Education Sciences, 9(79). https://doi.org/10.3390/ educsci9020079

[16] Goo Y, 2006, The Effects of Teaching English Vocabulary Reading through Educational Computer Games on Learning Achievement and Interest. Chung-Ang University.

[17] Wi J, Song I, 2011, Use of G-Learning Contents as Learning Tools and Analysis of Learning Effects: Focusing on the Application of Elementary School Mathematics. Journal of the Korean Game Society, 11: 55-62. http://dx.doi.org/10.7583/JKGS.2011.11.3.055

[18] Lim S, 2006, The Effect of English Reading Instruction with the Application of Computer Games on Children's Achievement and Interest of English Reading: 4th Grade Children in the Elementary School. Journal of the English Linguistic Science Association of Korea, : 1-18.

[19] Yoon H, 2020, A Study on the History and Development Direction of Korean Educational Serious Games. Journal of the Korean Game Society, 20: 101-110. https://doi.org/10.7583/JKGS.2020.20. 4.101

[20] Jeong E, Lee H, 2013, A Study on the Concepts and Categorization of Serious Games Based on Strategic Purposes and Applied Theories. Journal of Korea Game Society, 26: 61-69. http://dx.doi.org/10.22819/kscg.2013.26.3.008

[21] Felicia P, 2009, Digital Games in Schools, European Schoolnet, Brussels, Belgium, 1-41.

[22] Japan Machinery Industry Association, 2008, 2007 Serious Game Status Survey Report. Tokyo, Japan: Digital Contents Association Foundation, 66-95.

[23] Wi J, 2008, Online Game, Join Hands with Education, Hankyungsa, Seoul, Korea. 
[24] Kim J, Kim H, 2014, Essay on the Possibility for Grafting Computer Simulation Game on the Historical Education: The Case of Civilization 5. Hanyang University.

[25] Hong K, Jin S, 2006, Design and Implementation of a RPG edugame for Learning of History in Elementary School. Journal of The Korean Association of Information Education, 10: 327-340.

[26] Lee M, Kim K, 2010, A Serious Game Development for Historical Education Using OGRE Engine. Journal of Digital Contents Society, 11: 385-392.

[27] Kalypso Media Digital, 2010, Game Patrition. https://store.steampowered.com/app/33570/Patrician_II I/

[28] Mazurek MO, Engelhardt CR, 2013, Video Game Use in Boys with Autism Spectrum Disorder, ADHD Typical Development. Pediatrics, 132: 260-266. https://doi.org/10.1542/peds.2012-3956

[29] Kron FW, Gjerde CL, Sen A, et al., 2010, Medical Student Attitudes toward Video Games and Related New Media Technologies in Medical Education. BMC Medical Education, 10: 50. https://doi.org/10.1186/1472-6920-10-50

[30] Urguillo JC, 2010, Using Game Theory and Competition-Based Learning to Stimulate Student Motivation and Performance. Computers \& Education, 55: 566-575. https://doi.org/10.1016/j.comped u. 2010.02 .018

[31] Dickey MD, 2011, Murder on Grimm Isle: The Impact of Game Narrative Design in an Educational Game-Based Learning Environment. British Journal of Educational Technology, 42: 456-469. https://doi.org/10.1111/j.1467-8535.2009.01032.x

[32] Ebner M, Holzinger A, 2007, Successful Implementation of User-Centered Game Based Learning in Higher Education: An Example from Civil Engineering. Computers \& Education, 49: 873-890. https://doi.org/10.1016/j.compedu.2005.11.026

[33] Fengfeng K, 2008, Alternative Goal Structures for Computer Game-Based Learning. Journal of Computer-Supported Collaborative Learning, 3: 429-445. https://doi.org/10.1007/s11412-008-9048-2

[34] Jung Y, 2014, The Effects of Simulation Game-Based Learning on Academic Emotions and Achievement. Ewha Womans University.

[35] Pekrun R, Goetz T, Frenzel AC, et al., 2011, Measuring Emotions in Students' Learning and Performance: The Achievement Emotions Questionnaire (AEQ). Contemporary Educational Psychology, 36: 36-48. https://doi.org/10.1016/j.cedpsych.2010.10.002

[36] Akinsola MK, 2007, The Effect of Simulation-Games Environment on Students Achievement in and Attitudes to Mathematics in Secondary Schools. The Turkish Online Journal of Educational Technology, 6: 113-119.

[37] Sowunmi O, Aladejana F, 2013, Effect of Simulation Games and Computer Assisted Instruction on Performance in Primary Science, in Proceedings of the 2013 WEI International Academic Conference, Orlando, USA, 10-15.

[38] Microsoft Educator Center. https://education.microsoft.com/ko-kr/library?contentType=learningPath/

[39] Ministry of Education, 1995, High School Social Studies Curriculum Commentary. Ministry of Education, Seoul, Korea, 169.

[40] Collingwood RG, 1966, The Idea of History, Oxford University Press, Oxford, England, 269.

[41] Dray WH, 1995, History as Re-enactment, Oxford University Press, Oxford, England, 53.

[42] Kim H, 2000, Re-enactment, Is it an Alternative History Teaching Method? National History Teachers' Meeting, History Education, 49. 
[43] Lee M, 1998, Possibility of Re-Enaction as a Way of Learning History. Social Studies Education, 31: 133-157.

[44] Kim B, 2006, Types and Uses of Empirical History Learning in History Education. Kookmin University.

[45] Jung C, 2018, Games Application Methodology for History Education: Case Study of Developing a Serious Game for History Education. Journal of Korea Game Society, 18(6): 29-38. http://dx.doi.org/10.7583/JKGS.2018.18.6.29

[46] Gounaridou A, Siamtanidou E, Dimoulas C, 2021, A Serious Game for Mediated Education on Traffic Behavior and Safety Awareness. Education Sciences, 11(127). https://doi.org/10.3390/educsci1103012 7

[47] Chen MB, Wang SG, Chen YN, et al., 2020, A Preliminary Study of the Influence of Game Types on the Learning Interests of Primary School Students in Digital Games. Education Sciences, 10(96). https://doi.org/10.3390/educsci10040096

[48] Pombo L, Marques MM, 2020, The Potential Educational Value of Mobile Augmented Reality Games: The Case of EduPARK App. Education Sciences, 10(287). https://doi.org/10.3390/educsci10100287 